\title{
PROPAGATION OF PAPAYA (CARICA PAPAYA L.) CV. SHAHI THROUGH IN VITRO CULTURE
}

\author{
Protul Kumar Roy*, Shyamal Kumar Roy ${ }^{1}$ and Md Lokman Hakim \\ Institute of Food and Radiation Biology, Atomic Energy Research Establishment, \\ G.P.O Box 3787, Dhaka-1000, Bangladesh
}

Key words: In vitro culture, Explants, Regeneration, Carica papaya

\begin{abstract}
A large number of shoots regenerated from lateral buds and young leaves of Carica papaya L. cv. Shahi on MS supplemented with $1.0 \mathrm{mg} / \mathrm{l}$ zeatin and $0.2 \mathrm{mg} / \mathrm{l}$ NAA. Addition of $200 \mathrm{mg} / \mathrm{l}$ casein hydrolysate $(\mathrm{CH})$ to the medium increased the number of shoots per culture and incorporation of $2.0 \mathrm{~g} / \mathrm{l}$ activated charcoal (AC) to the medium resulted effective shoot growth with healthy leaf. While addition of $100 \mathrm{mg} / \mathrm{l}$ urea and $2.0 \mathrm{~g} / \mathrm{l}$ activated charcoal to the medium showed proper shoot elongation. Best rooting was obtained from shoots cultured on half-strength of MS fortified with $4.0 \mathrm{mg} / \mathrm{l}$ IBA.Within four weeks of transfer to the rooting medium, $90 \%$ microcuttings produced 12 - 14 roots. The regenerated plantlets were successfully transferred to potted soil. About $84 \%$ plantlets survived in the experimental field.
\end{abstract}

Papaya (Carica papaya L.) is an important fruit crop of Bangladesh and is one of the most popular versatile fruits, which is also used as vegetable. Papaya is a good source of pro-vitamin 'A' and ascorbic acid (Purnima and Sandhya 1988), important proteolytic enzyme such as papain and chymopapain with several commercial applications. Moreover, it also yields an alkaloid 'carpaine', which is used as a heart depressant, amoebacide and diuretic (Litz 1984).

Biologically papaya has three types such as male, female and bisexual but only female and bisexual types are productive. In commercial plantation it is very often found that male plants prevail as high as $30 \%$ and some times over $50 \%$ of the total (Jordan et al. 1983).

Conventional method of propagation like cutting or grafting has not been found successful in papaya. In this regard clonal propagation represents the economic way of continuously producing new uniform true-to-parental type planting materials of known superior lines. Cloning by in vitro technique has been proved as an excellent biotechnology of vegetative propagation specially for those, which are difficult to rooting (Conger 1981).

In vitro micropropagation system of papaya was reported by many researchers (Hossain et al. 1993, Rahman et al. 1992, Winnaar 1988 and Islam et al. 1993). But their reports were not satisfactory for large scale propagation of plantlets as well as successful field transfer. Thus considering the above facts, the present study was undertaken to develop a suitable protocol for in vitro propagation of papaya.

Young plants of Carica papaya L. cv. Shahi were collected from local nursery and planted in the research field of the Institute of Food and Radiation Biology, Atomic Energy Research Establishment, Savar, Dhaka for the collection of explants for present investigation. Plant materials, namely lateral buds and young leaves were collected in a beaker containing tap water to avoid desiccation. Surface sterilization was done under aseptic conditions in laminar air flow cabinet. They were surface sterilized with $70 \%$ ethyl alcohol $\left(1 \mathrm{~min}\right.$ ) followed by $0.1 \% \mathrm{HgCl}_{2}$ for $8 \mathrm{~min}$. After surface sterilization, lateral buds and young leaves were divided into small pieces (approx. $1.0-1.5 \mathrm{~cm}$ ). These were used as explants and cultured onto culture medium.

*Author for correspondence: <protulroy2006@yahoo.com>. ${ }^{1}$ Department of Botany, Jahangirnagar

University, Savar, Dhaka, Bangladesh. 
MS containing 3\% sucrose was used for all shoot regeneration studies. But half-strength MS was used for in vitro root formation. The influence of BA, zeatin, Kn and NAA, IAA, IBA were evaluated in various experiments as described below. All the chemicals were procured from the Sigma-Aldrich Co., USA.

Different concentrations and combinations of BA, zeatin, Kn and NAA were tested for their effect on shoot initiation from cultured explants. Media supplements such as casein hydrolysate (CH) (Merck, Germany) (100 - $300 \mathrm{mg} / \mathrm{l}$ ), urea, (Acros Organics, New Jersey, USA) (50 - 250 $\mathrm{mg} / \mathrm{l})$, activated charcoal (AC) (Sigma-Aldrich Co., USA) $(1.0-4.0 \mathrm{~g} / \mathrm{l})$ were added to the medium for the determination of their effects on shoot multiplication, elongation and growth, respectively. The shoots measuring 4 - $5 \mathrm{~cm}$ in length were excised from the elongation media and cultured individually in freshly prepared rooting media containing different concentrations and combinations of NAA, IAA and IBA.

Table 1. Effects of different concentrations and combinations of cytokinins and auxin on shoot proliferation of Carica papaya L. cv. Shahi from lateral bud and young leaf segment explants*.

\begin{tabular}{|c|c|c|c|c|}
\hline \multirow{3}{*}{$\begin{array}{l}\text { Growth } \\
\text { regulators } \\
(\mathrm{mg} / \mathrm{l})\end{array}$} & \multicolumn{4}{|c|}{ Explants } \\
\hline & \multicolumn{2}{|c|}{ Lateral bud } & \multicolumn{2}{|c|}{ Young leaf segment } \\
\hline & $\begin{array}{c}\text { \% of explants } \\
\text { produced } \\
\text { shoots }\end{array}$ & $\begin{array}{c}\text { Average number } \\
\text { of shoots/culture } \\
\pm \mathrm{SE}\end{array}$ & $\begin{array}{c}\text { \% of explants } \\
\text { produced } \\
\text { shoots }\end{array}$ & $\begin{array}{c}\text { Average number of } \\
\text { shoots/ culture } \\
\pm \mathrm{SE}\end{array}$ \\
\hline \multicolumn{5}{|r|}{ 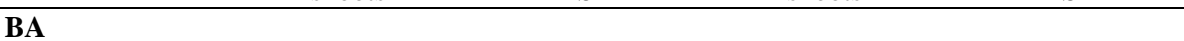 } \\
\hline 0.5 & 60 & $15.8 \pm 1.30$ & 10 & $2.1 \pm 1.25$ \\
\hline 1.0 & 70 & $16.5 \pm 2.25$ & 15 & $3.2 \pm 1.14$ \\
\hline 1.5 & 50 & $10.4 \pm 1.25$ & 20 & $5.4 \pm 1.14$ \\
\hline \multicolumn{5}{|l|}{$\mathbf{B A}+\mathbf{N A A}$} \\
\hline $0.5+0.1$ & 88 & $33.8 \pm 4.23$ & 25 & $8.5 \pm 2.55$ \\
\hline $1.0+0.1$ & 78 & $25.2 \pm 3.15$ & 45 & $10.8 \pm 2.35$ \\
\hline $1.5+0.1$ & 72 & $22.4 \pm 2.12$ & 22 & $5.2 \pm 1.15$ \\
\hline \multicolumn{5}{|l|}{ Zeatin } \\
\hline 0.5 & 52 & $23.6 \pm 3.22$ & 20 & $6.4 \pm 1.15$ \\
\hline 1.0 & 65 & $25.3 \pm 3.42$ & 28 & $10.5 \pm 2.18$ \\
\hline 1.5 & 80 & $22.4 \pm 3.66$ & 48 & $20.8 \pm 3.22$ \\
\hline \multicolumn{5}{|c|}{ Zeatin + NAA } \\
\hline $0.5+0.2$ & 48 & $14.2 \pm 2.62$ & 42 & $10.4 \pm 2.25$ \\
\hline $1.0+0.2$ & 90 & $34.2 \pm 4.22$ & 68 & $24.8 \pm 3.18$ \\
\hline $1.5+0.2$ & 62 & $14.4 \pm 2.14$ & 15 & $4.1 \pm 1.12$ \\
\hline \multicolumn{5}{|l|}{ Kn } \\
\hline 0.5 & 25 & $8.2 \pm 1.52$ & - & - \\
\hline 1.0 & 55 & $10.5 \pm 1.75$ & 20 & $8.4 \pm 1.32$ \\
\hline 1.5 & 68 & $14.4 \pm 2.12$ & 28 & $10.4 \pm 2.52$ \\
\hline \multicolumn{5}{|l|}{$\mathbf{K n}+\mathbf{N A A}$} \\
\hline $0.5+0.2$ & 40 & $14.2 \pm 2.48$ & 10 & $5.2 \pm 1.12$ \\
\hline $1.0+0.2$ & 78 & $22.8 \pm 3.14$ & 30 & $10.5 \pm 2.12$ \\
\hline
\end{tabular}

* Data recorded after six weeks of culture.

For acclimatization, the rooted plantlets were carefully removed from the culture tubes. The roots of the plantlets were gently washed under running tap water to remove agar attached to the root zone. Immediately after washing they were transferred to small earthen pots containing a mixture of soil, sand and compost in $2: 1: 1$ ratio. Finally acclimatized plantlets were transferred to the experimental field. 
In both the lateral bud and leaf segment explants, high percentage of shoot induction was observed in MS containing1.0 mg/l zeatin and $0.2 \mathrm{mg} / \mathrm{l}$ NAA (Table 1 ). In this combination an average of $34.2 \pm 4.22$ shoots regenerated from lateral bud explants whereas $24.8 \pm 3.18$ shoots regenerated from leaf segment explants (Table 1, Figs 1a, b). Rajeevan and Pandey (1986) were the first to report lateral bud cultures in papaya. Islam et al. (1993), Winnaar (1988) and Mondal et al. (1990) reported that MS with $0.5 \mathrm{mg} / \mathrm{l} \mathrm{BA}$ and $0.1 \mathrm{mg} / \mathrm{l} \mathrm{NAA}$ was optimum to regenerate highest number of shoots in Carica papaya from lateral bud explant, which was similar with the present second highest shoot regeneration medium as obtained in the present experiment.
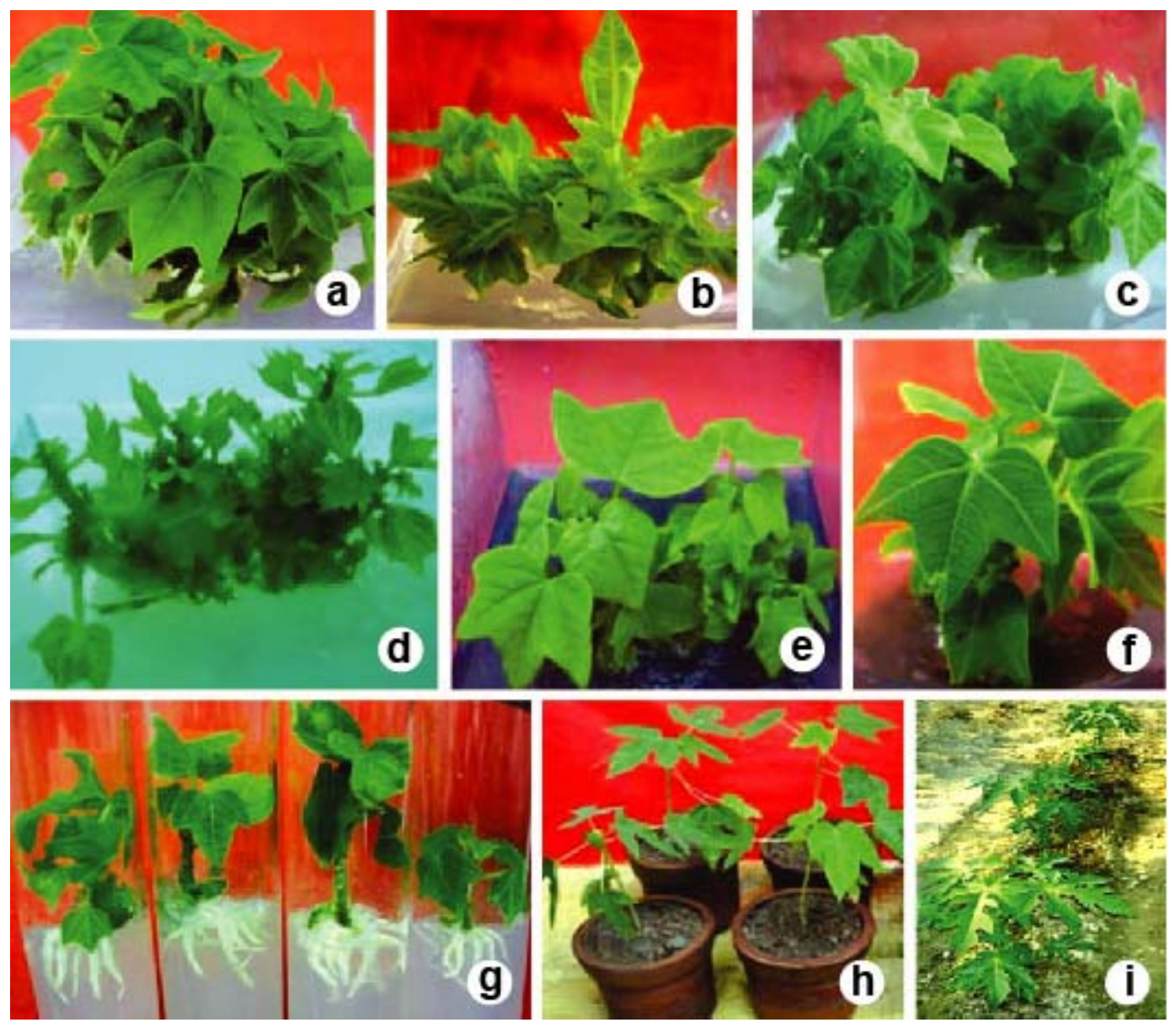

Fig 1a - i: In vitro regeneration of Carica papaya L. cv. Shahi. a-b. Multiple shoot formation from latreal bud (a) and leaf segment (b) explant on MS with $1.0 \mathrm{mg} / \mathrm{l}$ zeatin and $0.2 \mathrm{mg} / \mathrm{l} \mathrm{NAA}$. c-d. Positive effect of CH (200 mg/l) increase the number of shoots in lateral bud explant (c) and leaf segment explant (d). e. Healthy growth on MS containing $1.0 \mathrm{mg} / \mathrm{l}$ zeatin, $0.2 \mathrm{mg} / \mathrm{l} \mathrm{NAA}$ and $2.0 \mathrm{~g} / \mathrm{l} \mathrm{AC}$. f. Elongated shoots on MS with $1.0 \mathrm{mg} / \mathrm{l}$ zeatin, $0.2 \mathrm{mg} / \mathrm{l} \mathrm{NAA,} 100 \mathrm{mg} / \mathrm{l}$ urea and $2.0 \mathrm{~g} / \mathrm{l} \mathrm{AC}$. g. Root induction on half-strength of MS with $4.0 \mathrm{mg} / \mathrm{l}$ IBA. h. Regenerated plantlets in earthen pots containing soil, sand and compost $(2: 1: 1)$. i. Survived plants in experimental field. 
Addition of $200 \mathrm{mg} / \mathrm{l} \mathrm{CH}$ to the medium, increased the number of shoots (50 and 40 in case of lateral bud and leaf segment explant, respectively) per culture (Fig. 1c, d). Positive effect of activated charcoal (AC) on shoot growth was observed. Fruitful result was found on shoot growth with healthy leaves when $2.0 \mathrm{~g} / \mathrm{l} \mathrm{AC}$ was added to the medium (Fig. 1e). In the present investigation, urea (50 - $250 \mathrm{mg} / \mathrm{l})$ and activated charcoal (1.0 - $4.0 \mathrm{~g} / \mathrm{l})$ were added simultaneously to the medium to determine their effects on shoot elongation. The highest shoot length was observed when $100 \mathrm{mg} / \mathrm{l}$ urea and $2.0 \mathrm{~g} / \mathrm{l} \mathrm{AC}$ were added to the medium (Fig. 1f).

Table 2. Effects of different concentrations of auxins in half-strength MS on adventitious root formation of in vitro raised papaya shoots*.

\begin{tabular}{lccc}
\hline $\begin{array}{l}\text { Auxins } \\
(\mathrm{mg} / \mathrm{l})\end{array}$ & $\begin{array}{c}\text { \% of } \\
\text { shoots rooted }\end{array}$ & $\begin{array}{c}\text { No. of } \\
\text { roots/shoot }\end{array}$ & $\begin{array}{c}\text { Average length of } \\
\text { roots (cm) } \pm \text { SE }\end{array}$ \\
\hline NAA & - & - & - \\
3.0 & 10 & $4-6$ & $2.8 \pm 0.22$ \\
4.0 & 5 & $3-5$ & $2.5 \pm 0.18$ \\
5.0 & & & \\
IAA & 15 & $4-6$ & $2.6 \pm 0.33$ \\
2.0 & 25 & $6-8$ & $2.8 \pm 0.15$ \\
3.0 & 10 & $3-5$ & $3.2 \pm 0.25$ \\
4.0 & & & \\
IBA & 55 & $6-8$ & $2.8 \pm 0.24$ \\
2.0 & 70 & $8-10$ & $3.2 \pm 0.52$ \\
3.0 & 90 & $12-14$ & $3.5 \pm 0.45$ \\
4.0 & & & \\
IBA + IAA & 40 & $4-6$ & $2.5 \pm 0.12$ \\
$3.0+1.0$ & 55 & $6-8$ & $2.8 \pm 0.52$ \\
$4.0+1.0$ & 30 & $3-5$ & $2.5 \pm 0.15$ \\
$5.0+1.0$ & & & \\
\hline
\end{tabular}

${ }^{*}$ Data recorded after four weeks of culture.

Well developed and elongated shoots were excised and implanted in the rooting media containing half-strength MS with different concentrations and combinations of NAA, IAA, IBA. The best result was obtained in half-strength MS medium supplemented with $4.0 \mathrm{mg} / \mathrm{l}$ IBA (Table 2, Fig. 1g). Islam et al. (1993) obtained rooted papaya shoots in half-strength MS medium supplemented with $5.0 \mathrm{mg} / \mathrm{l}$ IBA, whereas Mondal et al. (1990) used half-strength of MS with 2.0 $\mathrm{mg} / \mathrm{l}$ IBA for in vitro rooting of papaya plantlets.

For acclimatization, the well rooted plantlets were transferred to small earthen pots containing a mixture of sterile soil, sand and compost $(2: 1: 1)$ (Fig. 1h). After hardening, plantlets were subsequently transferred to experimental field (Fig. 1i), where survival rate was $84 \%$. Thus, the present work demonstrates a protocol for in vitro propagation of Carica papaya L. cv. Shahi.

\section{References}

Conger BV 1981. Cloning agricultural plants via in vitro techniques. CRC Press, Boca Raton. Florida. pp. 164.

Hossain M, Rahman SM, Islam R and Joarder OI 1993. High efficiency plant regeneration from petiole explants of Carica papaya L. through organogenesis. Plant Cell Rep. 13: 99-102.

Islam R, Rahman SM, Hossain M and Joarder OI 1993. In vitro clonal propagation of papaya through culture of lateral buds from mature field-grown plants. Plant Tissue Cult. 3(1): 47-50. 
Jordan M, Cortes I and Montenegro G 1983. Regeneration of plants by embryogenesis from callus cultures of Carica candamarcensis. Plant Sci. Let. 28: 321-326

Litz RE 1984. Crop Species. In: Handbook of Plant Cell Culture. Vol. 2. Sharp WR, Evans DA, Amnivato PV and Yamada Y (eds.). Macmillan, New York. pp. 340-368.

Mondal M, Gupta S and Mukherjee BB 1990. In vitro propagation of shoot buds of Carica papaya L. (Caricaceae) var. Honey Dew. Plant Cell Rep. 8: 609-612.

Purnima S and Sandhya B 1988. Genotypic difference of in vitro lateral bud establishment and shoot proliferation in papaya. Biot. Cent. In: Indian Agric. Res. Ins., New Delhi- 110012, India.

Rahman SM, Hossain M, Joarder OI and Islam R 1992. Rapid clonal propagation of papaya through culture of shoot apices. Indian J. Hort. 49: 473-497.

Rajeevan MS and Pandey RM 1986. Lateral bud culture of papaya (Carica papaya L.) for clonal propagation. Plant Cell, Tissue and Organ Cult. 6: 181-188

Winnaar WD 1988. Clonal propagation of papaya in vitro. Plant Cell, Tissue and Organ Cult. 12: 305-310.

(Manuscript received on 3 March, 2012; revised on 17 November, 2012) 